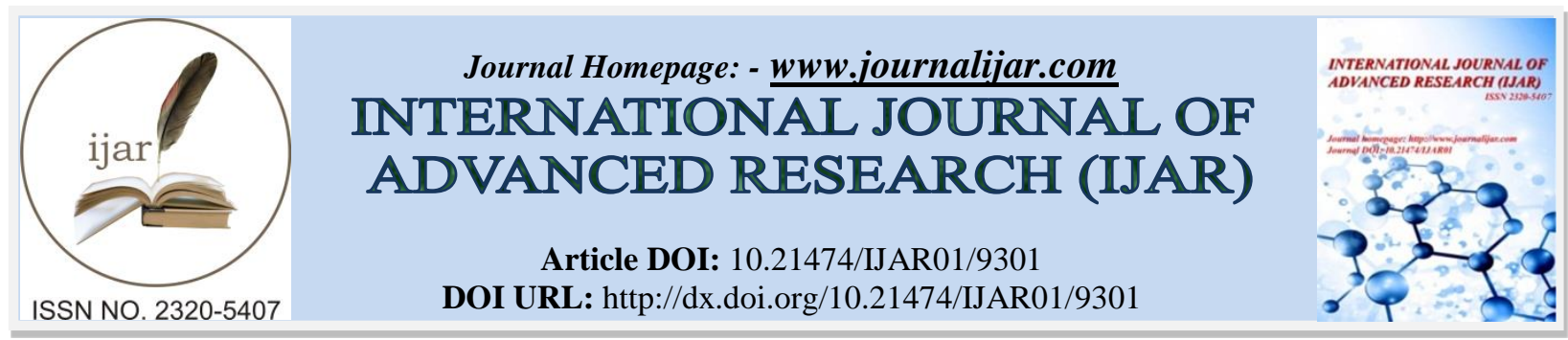

RESEARCH ARTICLE

\title{
FACTORS INFLUENCING IMPLEMENTATION OF THE NURSING PROCESS AMONG REGISTERED NURSES IN VIHIGA COUNTY REFERRAL HOSPITAL.
}

\author{
Lilian Amugitsi Isiaho'. \\ Department of Clinical nursing and health informatics, Masinde Muliro University of science and technology. \\ Phoebe Amessa Assanga ${ }^{2}$ \\ Intensive care unit, Trinity Hospital \\ Brian Wambaya ${ }^{3}$
}

\section{Manuscript Info}

...........................

Manuscript History

Received: 15 April 2019

Final Accepted: 17 May 2019

Published: June 2019

Key words:-

Nursing process, Vihiga county, Kenya.

\section{Abstract}

Objective. The objective of the study was to assess factors affecting implementation of nursing process among nurses in Vihiga county referral hospital. Design. The study was a descriptive cross-sectional study. Setting. The study was carried out in Vihiga County Referral Hospital Sample. Vihiga County was conveniently sampled.Stratified random sampling was used to sample nurses. The specific ward represented the strata for example the medical or surgical ward was the strata from which sampling was done $(n=50)$ Analysis. Data was analyzed through descriptive statistics, Independent samples' T-test and One-way analysis of variance. Main outcome measures. Factors influencing nursing process Results. Majority of the respondents 31 (62.6\%) agreed that staff shortage was a factor influencing nursing process. Majority of the respondents $29(58.6 \%)$ disagreed that lack of cooperation was a factor influencing implementation of nursing process. Of the 50 respondents, $35(70.7 \%)$ of the respondents agreed that lack of adequate equipment was a major hindrance to nursing process. $31(61.6 \%)$ of the respondents agreed that inadequate knowledge was a barrier. The ANOVA model showed significant differences amongst the different age groups $F(3,50)=9.403, p<0.05$. The partial eta squared showed that only $7 \%$ of the variability in the factors influencing nursing process could be attributed to the age $\eta^{2}=0$. 07 . No significant differences amongst the different nurse classification $F(2,50)=0.012, p=0.988$. And significant differences amongst the different work experience categories $F(4,50)=8.038, p<0.05$. Conclusion. The study established that nurses are working in stressful moments due to lack of enough nursing staffs: adequate staffing to be done. Registered nurses working in VCRH require training on implementation of nursing process.

Copy Right, IJAR, 2019,. All rights reserved.

Background:-

Nursing Process is a systematic problem-solving approach used to identify, prevent and treat actual or potential health problems and promote wellness. It has five steps- assessment, diagnosis, planning, implementation, and 
evaluation. Nursing process is an orderly, systematic manner of determining the patients, problem, making plans to solve them, initiating the plan and assisting others to implement it and evaluating the extent to which the plan was effective in solving the problem identified. (Yaura and walsh 1978). "The nursing process is a method for organizing nursing care to understand its functions, components and interactions, the nurse should have a working knowledge of the nature of the process. A process is series of steps or components leading to achievement of a goal. There are three characteristics of a process; purpose, organization and creativity" (Bevis 1978). The process is systematic because it occurs in a sequence, step by step, requires reasoning and critical thinking and is based on specific needs, focuses on the unique response of a person or group of people to the actual or potential health. Is a client centered approach, goal-oriented method of caring that provides framework to nursing care (Lefevre, 2006)?

According to current American and Canadian practice standards; of nursing practice demands the efficient use of nursing process and participation in activities that contribute to permanent de development of knowledge about this methodology and therefore there is need to establish nursing process in every department within the hospital as well was the community. The nursing process has several facts' is a form of documentation, means of organizing work, an educational tool and professional philosophy. It is also an interactive problem-solving process, systematic and individualized way to achieve outcome of nursing care. It accounts for individualized autonomy and freedom to make decisions and be involved in nursing care (Rushet al., 2007). The nursing process is accepted by nursing profession as a standard of providing ongoing nursing care that is adapted to individual patient needs. The nurse and the patient emerge as partners in a relationship build on trust and directed towards maximizing the patient's strengths, maintaining integrity and promotion adaptive response to stress (Beck,2011).

According to Carpenitto (2005), the nursing process is a widely accepted method that has been suggested as a scientific method to guide procedures and quality nursing care, more recently the process has been defined as a systematic and dynamic way to deliver nursing care operating though 5 related steps; assessing, nursing diagnosis planning implementing and evaluation. The nursing profession has witnessed a change towards a more independent practice with implicit knowledge of nursing care. With change has come the obligation to document not only the performed interventions medical and nursing but also the decision process explaining why a specific nursing action has been performed. (Billing's 2002). According to Lefevre (2006), lack of application of the nursing process leads to reduced job satisfaction, incorrect evaluation, scientific and practical retro graduation, reduction in the quality of care, excessive dependency to the physician, indisputable obedience, doing routine activities without thinking and a reduction in the patient's independence.

In Kenya, the nursing process has been in use but not fully implemented. Nurses provide $80 \%$ to $90 \%$ of both direct and indirect ministry of health core functions thereby making quality nursing care critical in overall provision of health care as well as achieving millennium development goals (MOMS, 2006) identified application of conceptual care frameworks as one of its priority strategies to improve quality nursing practice in Kenya. In order to improve quality nursing services in Kenya, the ministry of health began rolling down the training of nursing process to all high-volume hospitals in Kenya. It began with county referral hospitals then high-volume level 4 hospitals. So far, the ministry of health has trained about 47 hospitals in Kenya using the Kenyan model six-step training manual. They include; Jaramogi oginga Odinga hospital, Busia hospital, Machakos level 5 hospital, coast general hospital, Kisii general hospital, Meru hospital among others in every county plus level 4 hospitals.

The training at VCRH has never been done. There has been one training which was done as continuous medical evaluation to the nurse during the introduction to new NANDA I. Very few nurses attended that training. There has never been in service training of nurses on implementation of nursing process. It has always been that most nurses who are new in the field were able to come up new ways of making nursing process. The target population was the nurse managers and nurse practitioners from all sections of the hospital but unfortunately very few nurses turned up. For training needs all carder of nursing staff to be there due not change overs kin the facility. Following the training, the trainees were mandated to do an on-job training to the reminder of the no-staff. But there has been increased level of nursing process in implementation. Nursing process implementation could be highly influenced by different factors that can lead to Poor quality of nursing care, disorganization of the service, conflicting roles, medication error, poor diseases prognosis, readmission, dissatisfaction with the care provided, and increased mortality. These problems are manageable if a nurse can properly implement nursing process. Therefore, the main aim of this study was to assess factors affecting implementation of nursing process among nurse in hospital in VCRH. The finding will provide pragmatic evidence for educators, clinicians, program planner, decision makers to design a new and/or strengthen the existing nursing process and it also served as a baseline for future researchers 


\section{Methods:-}

Permission was sort from the college Research Committee and the nursing Research and Ethical Review committee of VCRH through the medical superintendent and prior to commencement of the study. Potential respondents approached in groups and explained the purpose of the study and the impacts and measures taken to observe confidentiality will be distributed. Informants were advised of the voluntary nature of the study and given option to withdraw from the study at any stage without being subjected any penalty. Prior to the commencement of the questionnaires, they were required to fill the written informed consent to allow them participate in the study. No further approval was needed since the project did not require access to patients or personal data.

\section{Research Design}

Research design is a plan for collecting and utilizing data so that desired information can be obtained with sufficient precision (Miles and Huberman, 2004). The design adopted for this study was descriptive survey design this because the study was trying to find out what the nurse perceived to be factors that influence utilization of the nursing care plan in patient care

\section{Study setting}

The study was conducted at Vihiga county referral Hospital. Vihiga County Referral Hospital is located in Vihiga County Mbale town along Kakamega Kisumu highway. Vihiga county referral Hospital is selected because there is no similar evidence of such study having been done in the study area. The area was also selected because it is the only organization that the researcher was able to find the nurses and other healthcare providers. The hospital has several departments including; Surgical ward, Pediatrics, Maternity, Postnatal, Medical Training School, CCC, Renal Unit. It is therefore believed that the study area gave a wide and varied view of the problem under study.

\section{Participants}

Study population is a study of a group of individuals taken from the general population who share a common characteristic (Mugenda and Mugenda, 1999). The target population was nurses working in the units that utilize the nursing process that is the medical and surgical ward. Participants who were included in this study had to meet the following criteria; Staff nurses who were practicing nursing for a minimum of 3 months in VCRH and willing to voluntarily participate in the study and working in VCRH. A subset of the entire population was used for the study. Stratified was used in that the specific ward represents the strata for example the medical or surgical ward was the strata from which systematic sampling was done. In order to get the proportionate allocation of each allocation of each ward the following formula was used.

\section{Questionnaire}

The study instrument was structured questionnaire, because; It permitted greater depth of response, it was economical in terms of time and money, it was easy to analyze and closed-ended questions are easier to formulate. The dependent variable was utilization of nursing care plan. Self-report questionnaire was designed to draw out information in written response in relation to attitude, believes and knowledge regarding implementation of nursing process. Patients audit chart to provoke information about patient's satisfaction about nursing service following admission. Self-report questionnaire was originally devised by (Rapley, O'Connell and Tibet 2000) and modified for current study. Validity is the degree to which an instrument measures what is supposed to be measured. Validity is the degree to which results obtained from the analysis of data actually represent the phenomenon under the study (Mugenda et al 2003). The validity of both instruments was established by a thorough review of the literature and conducting a pilot study. In relation to consulting expert opinions, a group of two nurses' educators examined both instruments, which consist of my research supervisor and research lecture. On their advice, small changes were made on the questionnaire and patient audit charts. Reliability is the measure of degree to which a research instrument yields consistent result after repeated trials. I did pre-test the questionnaire and used standardized protocol of asking questions for all respondents without changing their meaning so as to increase consistency of information collected hence ensuring reliability and validity.

\section{Data Analysis}

Data analysis was done using the statistical program for social sciences (SPSS) version 25. Inferential and descriptive statistics were used to analyze data. Descriptive analysis of data was done using the mean, frequencies 
and percentages. In this study association between the study variables was assessed by a two-tailed probability value of $p<0.05$ for significance. Visual inspection of the data illustrated that missing data appeared to be missing at random. After visual inspection, in order to further examine the pattern of missing data, the researcher evaluated whether the data was missing completely at random (MCAR). The researcher utilized Little's MCAR test (Schlomer et al., 2010) which employs a chi-square statistical analysis and assumes the null hypothesis, that missing data is missing completely due to randomness. Each question was coded and entered in SPSS (Barohn et al, 2012). The findings were entered in the variable view of the Statistical Package for Social Sciences (SPSS) version 25.0 screen, each questionnaire at a time, starting with first to last questionnaire (Cohen, 2011). The researcher conducted analyses of normality, for the outcome variable, prior to hypothesis testing by examining kurtosis and skewness of the data. In order to test and identify possible outliers in the data, graphical assessment visuals, including scatter and box plots were used. Elimination of observed outliers was based on a case by case basis, dependent on standard deviations, and on normality and homogeneity of variance assessments. Normality was assessed using examination of the histograms by seeing how they related or deviate against a normal bell curve distribution and observing the levels of kurtosis and skewness present.

Univariate analysis was used to describe the distribution of each of the variables in the study objective, appropriate descriptive analysis was used to generate frequency distributions, tables and other illustrations used to analyze the social treatment. Bivariate and multivariate analysis was used to investigate the strength of the association and check differences between the outcome variable and other independent variables. Alpha level for all the computations was considered $\mathrm{p}<0.05$.

\section{Results:-}

Out of the 60 questionnaires distributed, 50 were correctly filled and returned which represented a response rate of 83 percent. According to Mugenda and Mugenda (2003) a response rate of 50 percent is adequate, a response rate of 60 percent is good, and a response rate of 70 percent is very good. Therefore, the 83 percent response rate reported for this study formed an acceptable basis for drawing conclusions. While we should not expect full response in studies where responding is voluntary, scholars utilizing questionnaires should aim for a high response rate (Baruch \& Holtom, 2008). Firstly, the study asked the respondents to indicate their background characteristics based on the gender, nurse classification, work experience; age-bracket and education level. The summary of their responses is given in Table 1.

Table 1:- Background characteristics of respondents

\begin{tabular}{|c|c|c|c|}
\hline Demographics & & Frequency & Percent \\
\hline \multirow[t]{3}{*}{ Gender } & Male & 22 & $43.1 \%$ \\
\hline & Female & 28 & $56.9 \%$ \\
\hline & Total & $\mathbf{5 0}$ & $\mathbf{1 0 0 . 0}$ \\
\hline \multirow[t]{4}{*}{ Nurse classification } & Registered Nurses & 7 & $13 \%$ \\
\hline & Enrolled Nurse & 5 & $9 \%$ \\
\hline & Registered community health nurse & 38 & $83 \%$ \\
\hline & Total & 50 & $100 \%$ \\
\hline \multirow[t]{4}{*}{ Work Experience } & Below 2 years & 5 & $9 \%$ \\
\hline & $2-5$ years & 31 & $61 \%$ \\
\hline & Above 5 years & 14 & $30 \%$ \\
\hline & Total & 50 & 100.0 \\
\hline \multirow[t]{5}{*}{ Education level } & Certificate & 0 & $0.0 \%$ \\
\hline & Diploma & 29 & $57 \%$ \\
\hline & Higher diploma & 16 & $34 \%$ \\
\hline & Undergraduate & 5 & $9 \%$ \\
\hline & Total & 50 & 100.0 \\
\hline \multirow[t]{4}{*}{ Age Bracket } & $25-30$ years & 18 & $35 \%$ \\
\hline & 31-35 years & 24 & $48 \%$ \\
\hline & Above 36 years & 9 & $17 \%$ \\
\hline & Total & 50 & 100.0 \\
\hline
\end{tabular}


Findings in Table 1 revealed that, of the fifty (50) respondents interviewed, $22(43.1 \%)$ were male while 28 $(56.9 \%)$ were females. Majority of the respondents $38(83 \%)$ were registered community nurses, while $5(9 \%)$ were enrolled nurses. $31(61 \%)$ of the respondents had a work experience of $2-5$ years while $5(9 \%)$ had an experience of below 2 years. Majority of the respondents 16 (34\%) had higher national diploma, and 5 (9\%) had undergraduate degree. Findings in Figure 1 revealed that, majority of the respondents 31 (62.6\%) agreed that staff shortage was a factor influencing nursing process. Majority of the respondents $29(58.6 \%)$ disagreed that lack of cooperation was a factor influencing implementation of nursing process. Of the 50 respondents, $35(70.7 \%)$ of the respondents agreed that lack of adequate equipment was a major hindrance to nursing process. $31(61.6 \%)$ of the respondents agreed that inadequate knowledge was a barrier. The results also show that $41(83.7 \%)$ disagreed that poor team work was a major factor influencing nursing process. Figure 1 below summarizes the responses on the items.

Figure 1: Factors influencing nursing process

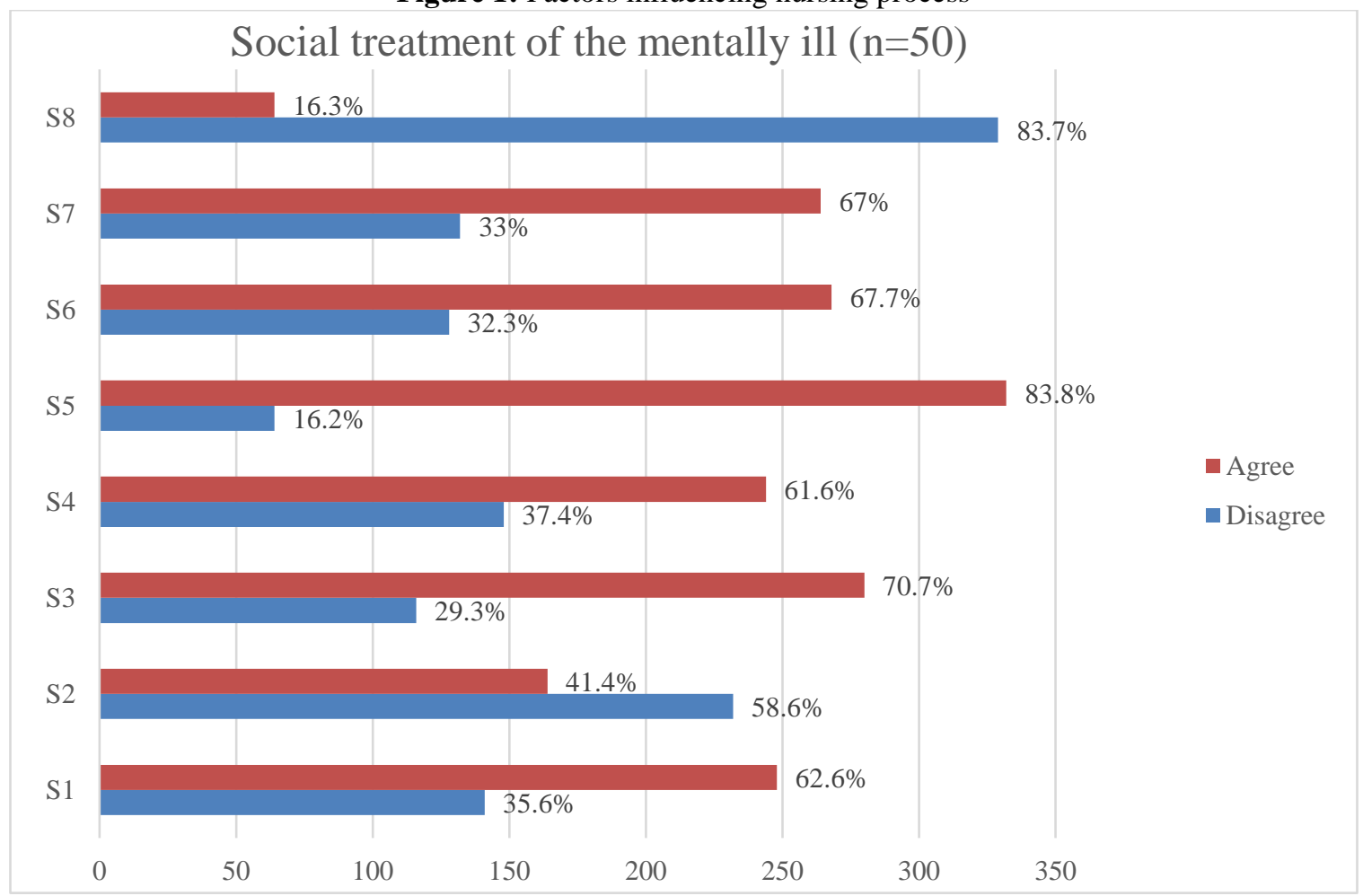

Key

S1- Staff shortage

S2- Lack of cooperation

S3- Lack of adequate equipment

S4- Inadequate knowledge

S5- Nurses attitude

S6- Patients records

S7- Poor supervision

S8-Poor team work

Bivariate analysis of implementation of nursing process and Demographic characteristics

The study also sought to check possible differences in the factor influencing nursing process amongst the various demographic characteristics. To achieve this one-way ANOVA (more than 3 levels) and independent t-test (two levels) were used, and the results were considered significant at a probability of 0.05 .

\section{Differences in factors influencing nursing process amongst respondents in different age brackets}


The ANOVA model showed significant differences amongst the different age groups $F(3,50)=9.403, p<0.05$. The partial eta squared showed that only $7 \%$ of the variability in the factors influencing nursing process could be attributed to the age $\eta^{2}=0.07$.

Differences in factors influencing nursing process amongst respondents in different nurse classification The ANOVA model showed no significant differences amongst the different nurse classification $F(2,50)=0.012, p$ $=0.988$. The partial eta squared showed that none of the variability in the factors influencing nursing process could be attributed to the nurse classification $\eta^{2}=0.00$.

Differences in factors influencing nursing process amongst respondents with work experience The ANOVA model showed significant differences amongst the different work experience categories $F(4,50)=$ $8.038, p<0.05$. The partial eta squared showed that only $8 \%$ of the variability in the factors influencing nursing process could be attributed to the work experience $\eta^{2}=0.08$.

Differences in factors influencing nursing process amongst respondents with different education levels The ANOVA model showed no significant differences amongst the different education levels $F(4,50)=1.860, p$ $>0.05$. The partial eta squared showed that only $2 \%$ of the variability in the factors influencing nursing process could be attributed to the education levels $\eta^{2}=0.02$.

Differences in factors influencing nursing process amongst respondents with different gender

The Independent t-test results showed no significant differences between males $(\mathrm{M}=5.05, \mathrm{SD}=1.129)$ and females $(\mathrm{M}=4.87, \mathrm{SD}=.174)$ with regards to factors influencing nursing process $t(50)=1.492, p=0.137$. The results are as shown in the table below.

Table 2: Summary of bivariate analysis of demographic characteristics and factors influencing nursing process

\begin{tabular}{|l|l|l|l|}
\hline Variable & F & Sig & Partial Eta Squared \\
\hline Age bracket & 9.403 & 0.00 & .070 \\
\hline Nurse classification & 0.012 & 0.988 & 0.00 \\
\hline Work experience & 8.038 & 0.00 & 0.79 \\
\hline Education level & 1.860 & 0.117 & 0.02 \\
\hline
\end{tabular}

\section{Discussion:-}

The purpose of this study was to assess factors affecting implementation of nursing process among nurses in VCRH. The study revealed that majority of the respondents $31(62.6 \%)$ agreed that staff shortage was a factor influencing nursing process. In addition, most of the respondents $29(58.6 \%)$ disagreed that lack of cooperation was a factor influencing implementation of nursing process. In a study aimed at investigating the barriers towards implementation of the nursing process inn selected hospital in urumia, the respondents mentioned lack of sufficient information about the concept of nursing process, lack of believe in using the nursing process, excess number of patients and shortage of nurse's son that nurses do not have enough time to use nursing procession all the patients in their care (Moghaddam et al.2011). Consistent with the current findings, an experimental qualitative research done at Kakamega County Referral Hospital in the year 2015 by Daniel Sakwa on factors contributing to lack of implementation of the nursing process showed that the main factors hindering implementation of nursing process were, shortage of staffs, lack of cooperation among staffs and lack of adequate equipment and supplies and promoting factors to be considered in implementing the nursing process were; motivation, supervision, staffing and nursing process education

In the current study, $35(70.7 \%)$ of the respondents agreed that lack of adequate equipment was a major hindrance to nursing process and $31(61.6 \%)$ of the respondents agreed that inadequate knowledge was a barrier. Similar studies have been done by De La Cuesta (1983) and he observed that the major records in the nursing process experienced a different type of implementation. According to de cuesta, the major barrier to full implementation of nursing process was the care plans. Care plans were inconsistently written and a medical rather than a nursing focus. Nurse's perceived care; plan to be superfluous and argued that they do not have time for them. When they were written, nurses found it difficult to state the problems and express diagnostic concept in writing. Moreover, for nursing staff, 
the relationship of care plan to the welfare of the patients was far from clear, care plans were regarded as imposed formalities to be field in when time was left to do them, sometimes for administrative than for practical purposes. In a study by Omondi, Ayieko \& Wakasiaka, 2012, findings showed that most nurses had no experience on nursing care plan. The staffs were few and there they had no enough time to write the care plan. There was lack of administrative support on materials to implement nursing process; supplies were inadequate. Adequate staffing were the major factors influencing implementation of the nursing process.

\section{Conclusion \& Recommendation:-}

The study established that nurses are working in stressful moments due to lack of enough nursing staffs: adequate staffing to be done. Registered nurses working in VCRH require training on implementation of nursing process. During selection while employing, one rule should be that the nurse to be employed should know how to write a nursing care plan of patients. Proper supervision to take place to make sure there is full implementation of nursing process by ward nurse in charges

\section{Reference:-}

1. Cavanagh SJ (1992) Job satisfaction of nursing staff working in hospitals. J Adv Nurs 17: 704-711.

2. CGS (2010) Nurse Practice Act

3. Darvas JA, Hawkins LG (2002) What makes a good intensive care unit: a nursing perspective. Aust Crit Care 15: 77-82.

4. De Freitas MC, Queiroz TA, de Souza JA (2007) [The nursing process according to the view of nurses from a maternity]. Rev Bras Enferm 60: 207-212.

5. Global health council (2010) Building a Winning Nursing Work Force for HIV-Care in Ethiopia.

6. Griffith CH 3rd, Wilson JF, Desai NS, Rich EC (1999) Housestaff workload and procedure frequency in the neonatal intensive care unit. Crit Care Med 27: 815-820.

7. Hale CA, Thomas LH, Bond S, Todd C (1997) The nursing record as a research tool to identify nursing interventions. J Clin Nurs 6: 207-214.

8. J Schaefer (2010) Nursing process and its determinant factors.

9. Lima AF, Kurcgant P (2006) [The nursing diagnosis implementation process at the University Hospital of the University of São Paulo]. Rev Esc Enferm USP 40: 111-116.

10. Lima AF, Kurcgant $P$ (2006) Meanings of the nursing diagnosis implementation process for nurses at a university hospital. Rev Lat Am Enfermagem 14: 666-673.

11. Oates RK, Oates P (1995) Stress and mental health in neonatal intensive care units. Arch Dis Child Fetal Neonatal Ed 72: F107-110.

12. Reason J (1990) Human error. Cambridge, UK: Cambridge University Press.

13. Reppetto MA, de Souza MF (2005) [Evaluation of nursing care systematization through the phases of nursing process performance and registration in a teaching hospital]. Rev Bras Enferm 58: 325-329.

14. S Carlson (2010) Nursing Process

15. WHO (2006) The World Health Report 2006. 